\title{
A cooling and two-step depressurization foaming approach for the preparation of modified HDPE foam with complex cellular structure
}

\author{
Zhanjia Wang $^{1,2}$, Xiangyu Ding ${ }^{1,2}$, Mingming Zhao ${ }^{1,2}$, Xiangdong \\ Wang $^{1,2}$, Guozhi Xu ${ }^{1,2}$, Aimin Xiang ${ }^{1,2}$, Hongfu Zhou ${ }^{1,2, *}$ \\ ${ }^{1}$ School of Materials and Mechanical Engineering, Beijing Technology and Business \\ University, Beijing 100048, People's Republic of China \\ ${ }^{2}$ Beijing Key Laboratory of Quality Evaluation Technology for Hygiene and Safety of \\ Plastics, Beijing 100048, People's Republic of China
}

\begin{abstract}
This article reports on the fabrication of modified high-density polyethylene (HDPE) foams with complex cellular structure (CCS) using supercritical $\mathrm{CO}_{2}$ as a physical blowing agent by a cooling and two-step depressurization method. HDPE was modified by dicumyl peroxide (DCP) and carbon nanotubes (CNTs) to improve its viscoelasticity and foaming behavior. The gel content test demonstrated that the cross-linking structure formed in the modified HDPE samples. Compared with that of neat HDPE, the viscoelasticity of modified HDPE was improved largely, which was characterized by rotational rheometer and torque rheometer. The introduction of DCP and CNTs had a slightly effect on the thermal behaviors of HDPE. The foaming properties of various HDPE samples showed that the cross-linking structure caused by DCP improved the
\end{abstract}

${ }^{*}$ Corresponding author: Tel.: $+\mathbf{8 6} 1068983954$.

E-mail address: zhouhongfu@th.btbu.edu.cn (Hongfu Zhou). 
foamability of HDPE and CNTs acted as a nucleating agent for cell nucleation. The degree of the first-step depressurization was critical to control the CCS evolution in HDPE foam.

Keywords: Complex cellular structure; cooling and two-step depressurization synergy method; HDPE; Foam; $\mathrm{CO}_{2}$

\section{Introduction}

Polymeric foams with complex cellular structure (CCS) (or bimodal cellular structure) possessed merits of both large and small cell structures. Large cells could reduce the bulk density, and small cells helped to enhance the mechanical and thermal insulation properties $[1,2]$. For this reason, the polymeric foam with CCS had been widely applied in many fields, such as packaging materials, chemical industry, construction, and so on.

Generally, four methods for the fabrication of the polymeric foam with CCS had been reported, which were co-blowing agent method [1-3], two-step depressurization method [4-8], polymer blending system method [9-13], as well as cooling and depressurization method [14]. Polystyrene (PS) foams with CCS were prepared using water and n-butane as co-blowing agents in extrusion and it was found that the CCS could be tuned by n-butane/water/silica content and die temperature [2]. Ma et al. found that the compressive and dynamic mechanical properties of the polycarbonate (PC) foam with CCS were higher than those of PC foam with mono-porous cell structure (MCS) [5]. PS foam with CCS was prepared using a two-step depressurization method by Bao et al. They found that with the similar density, the tensile strength and modulus increased with large cells decreasing when the cell size of large cells was larger than $25 \mathrm{~mm}$. When the volume fraction of large cell was more than $32 \%$, the impact strength decreased with the large cell increasing [6]. Stearic acid (SA) and organic montmorillonite (OMMT) were added into ethylene vinyl acetate (EVA), leading to the formation of CCS in EVA/SA/OMMT foam. Compared with those of neat EVA foams, the density of 
EVA/SA/OMMT foam became lower, and the peel strength and elongation-at-break of EVA/SA/OMMT foam were increased [11]. The cross-linked PS/polymethyl methacrylate (PMMA) blending foam with CCS was produced by Kohlhoff et al. Two cell nucleation took place in the PS matrix and the PMMA-rich domains successively, due to the elasticity difference between the binary phase of PS and PMMA. The quantity of the small cells in the cell walls increased with the content of the MMA monomer [13]. Polypropylene (PP) foam with CCS was fabricated by Li et al. using cooling and depressurization method. The results demonstrated the rapid cooling which led to the sharp decrease of the $\mathrm{CO}_{2}$ solubility in PP caused the first nucleation. With the eventual depressurization, these cell nucleuses grew to big cells, as well as some small cells produced, resulting in the PP foam with CCS [14].

Through the above literatures, it could be found that the investigations about CCS were mainly focused on amorphous polymer and polymer with low crystallinity. The research on high-density polyethylene (HDPE) foams with high crystallinity was concentrated on MCS [15-19], while few studies on HDPE foams with CCS were reported. Compared with amorphous polymer and polymer with low crystallinity, HDPE possesses the lower degree of branching and the stronger crystallization ability, leading to narrower foaming processing window and lower foam ability of HDPE. Therefore, the preparation of HDPE foams with CCS was relatively difficult and a big challenge for the researchers.

In order to solve the above problem, HDPE was cross-linked by dicumyl peroxide (DCP) in this paper. Moreover, carbon nanotubes (CNTs) were introduced into the foam system acting as a nucleating agent to decrease the cell nucleated energy barrier and increase the cell density. Then, a new methodology (cooling and two-step depressurization method) was proposed for the preparation of HDPE foam with CCS. The effect of the addition of DCP and DCP/CNTs to HDPE as well as the degree of the first depressurization $\left(\Delta \mathrm{P}_{1}\right)$ on the formation and evolution of CCS were investigated. 


\section{Experimental}

\subsection{Materials}

HDPE (5000S) with the melt flowing index of $1.02 \mathrm{~g} / 10 \mathrm{~min}$ at $190{ }^{\circ} \mathrm{C} / 2.16 \mathrm{~kg}$ and the density of $0.92 \mathrm{~g} / \mathrm{cm}^{3}$, was provided by PetroChina Co. Ltd. DCP was purchased from Sinopharm Chemical Reagent Co. Ltd. Multi-walled CNTs having a particle size of 7-11 $\mathrm{nm}$ and a more than $90 \%$ purity, were supplied by Beijing CNano Technology Co. Ltd. Xylene was provided by Tianjin Yongda Chemical Reagent Co. Ltd.

\subsection{Preparation of various HDPE samples}

HDPE, DCP, and CNTs were mixed in a Haake internal mixer at $190{ }^{\circ} \mathrm{C}$, with a mixing time of $15 \mathrm{~min}$ and mixing speed of $60 \mathrm{rpm}$ to prepare various HDPE samples, according to the formula shown in Table 1. The additives (DCP and CNTs) used the unit of "parts per hundred resin" (phr) for the formula. The resultant mixed HDPE samples were transferred to a mold, preheated at $160{ }^{\circ} \mathrm{C}$ and held for $5 \mathrm{~min}$, then pressed at 10 $\mathrm{MPa}$ for $3 \mathrm{~min}$, finally cooled to room temperature to obtain sheet samples of $2 \mathrm{~mm}$ in thickness for further characterization or foaming process.

\section{Table 1}

Samples of various high-density polyethylene (HDPE) blends.

\begin{tabular}{cccc}
\hline Samples & HDPE (phr) & DCP (phr) & CNTs (phr) \\
\hline HDPE (1\#) & 100 & 0 & 0 \\
HDPE/DCP (2\#) & 100 & 0.25 & 0 \\
HDPE/DCP/CNTs (3\#) & 100 & 0.25 & 0.10 \\
\hline
\end{tabular}

Dicumyl peroxide and carbon nanotubes are denoted as DCP and CNTs, respectively.

\subsection{Preparation of various HDPE foaming samples}


Various HDPE foams were produced through two kinds of batch foaming methods: (i) one-step depressurization method and (ii) cooling and two-step depressurization method, using $\mathrm{CO}_{2}$ as physical blowing agent. In a stainless-steel autoclave, the sheet HDPE sample and $\mathrm{CO}_{2}$ were held at a temperature of $200{ }^{\circ} \mathrm{C}$ and a pressure of $20 \mathrm{MPa}$ for $2 \mathrm{~h}$ to ensure the HDPE sample was fully dissolved and then the temperature was cooled to $135^{\circ} \mathrm{C}$ at $1.5{ }^{\circ} \mathrm{C} / \mathrm{min}$. Subsequently, for method (i): quenched to atmosphere pressure within 3 seconds; or for method (ii): the pressure was reduced for a designed value (1.0, 1.5, 3.0, 4.0, 5.0 MPa), kept for 20 minutes and then quenched to atmospheric pressure within 3 seconds. The change of pressure in the autoclave with time was shown in Fig. 1.

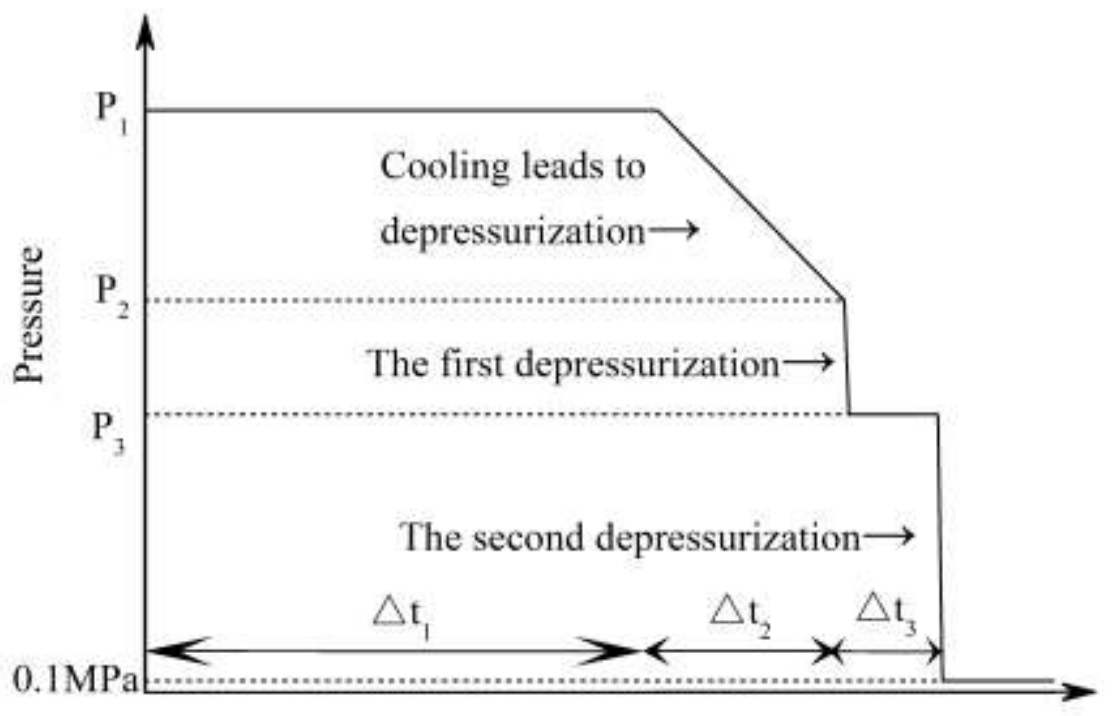

Time

Fig. 1. Curve of pressure variation in the autoclave with time in cooling and two-step depressurization foaming process, $\mathrm{P}_{1}: 20 \mathrm{MPa} ; \mathrm{P}_{2}$ : the pressure in the autoclave (about 15.0 $\mathrm{MPa}$ ) when the temperature of the autoclave was cooled to $135{ }^{\circ} \mathrm{C}$; $\mathrm{P} 3$ : the remaining pressure in the autoclave after the first depressurization $(1.0,1.5,3.0,4.0,5.0$ $\mathrm{MPa}), \Delta \mathrm{t}_{1}$ : the first holding time $(2 \mathrm{~h}) ; \Delta \mathrm{t}_{2}$ : cooling time: the temperature of the autoclave cooled from $200{ }^{\circ} \mathrm{C}$ to $135{ }^{\circ} \mathrm{C}$ (about $\left.45 \mathrm{~min}\right) ; \Delta \mathrm{t}_{3}$ : the second holding time (20 min). 


\subsection{Characterizations}

\subsubsection{Measurement of Gel Content.}

Various HDPE samples were washed with xylene in a Soxhlet extractor until their weights were constant. The insoluble parts of various HDPE samples were dried in oven at $60{ }^{\circ} \mathrm{C}$ for $4 \mathrm{~h}$ to allow the xylene to evaporate completely. Every sample was tested three times, and the average value was taken. The gel contents of the HDPE samples (1\# and 2\#) and the HDPE sample of $3 \#$ were computed by the equations (1) and (2), respectively:

$$
\begin{aligned}
& \text { gel content }(\%)=\frac{W_{g}}{W_{0}} \times 100 \% \\
& \text { gel content }(\%)=\frac{W_{g}-W_{c}}{W_{0}-W_{c}} \times 100 \%
\end{aligned}
$$

Where $W_{0}, W_{\mathrm{g}}$, and $\mathrm{W}_{\mathrm{c}}$ represented the weights of the initial polymer, dried insoluble part of samples, and carbon nanotubes, respectively.

\subsubsection{Differential Scanning Calorimetry (DSC).}

DSC instrument (Q100, TA, USA) was conducted to determine the crystallization and melting behaviors of various HDPE samples purged with nitrogen. Samples were equilibrated to $220{ }^{\circ} \mathrm{C}$ rapidly, held in the molten state for 5 min to erase prior thermal and stress histories, and then cooled down to $40{ }^{\circ} \mathrm{C}$ at a rate of $20{ }^{\circ} \mathrm{C} / \mathrm{min}$. Finally, samples were re-heated to $220{ }^{\circ} \mathrm{C}$ at the same rate. The crystallinity $(\chi)$ of various HDPE samples was calculated by the equation (3):

$$
\chi(\%)=\frac{\Delta H_{c}}{\Delta H_{c}^{0}} \times 100 \%
$$

Where $\Delta H_{c}$ and $\Delta H_{c}^{0}$ were the crystallization enthalpy of various HDPE samples and neat HDPE that $100 \%$ crystallized, respectively. $\Delta H_{c}^{0}$ was considered to be 290.0 J/g [20]. 


\subsubsection{Dynamic Rheometer.}

The dynamic rheological properties of various HDPE samples were tested using a rotational rheometer (ARES Rheometer, TA, USA) at $220{ }^{\circ} \mathrm{C}$ with a pair of parallel plates (20 $\mathrm{mm}$ in diameter with a gap of $1.0 \mathrm{~mm}$ ). The complex viscosity $\left(\eta^{*}\right)$, storage modulus $\left(\mathrm{G}^{\prime}\right)$ and loss factor $(\tan \delta$ ) were detected at various shear rates. The range of shear rate was from 0.1 to $100 \mathrm{rad} / \mathrm{s}$, and the maximum strain was set at $0.5 \%$, to confirm that these conditions were within the linear viscoelastic region under nitrogen.

\subsubsection{Scanning Electron Microscope (SEM).}

The cellular morphology of various HDPE foaming samples was observed using SEM (FEI Quanta FEG). The foaming samples for SEM were prepared by cryogenically cutting the obtained foam samples and gold sputtering the fractured cross sections.

\subsubsection{Foaming Property.}

The expansion volume ratio $(\Phi)$ of various HDPE foaming samples was calculated by the equation (4):

$$
\Phi=\frac{\rho_{p}}{\rho_{f}}
$$

Where $\rho_{p}$ and $\rho_{f}$ were the bulk densities of the pre-foam and post-foam samples in $\mathrm{g} / \mathrm{cm}^{3}$, respectively, which were measured by a density balance (Sartorius, Goettingen, Germany).

By assuming the cells were spherical, the cell densities, $\mathrm{N}_{0}$, in cells $/ \mathrm{cm}^{3}$, were defined using equation (5):

$$
N_{0}=\left[\frac{n M^{2}}{A}\right]^{\frac{3}{2}} \Phi
$$

where $n$ was the number of cells in the SEM micrograph, M was the magnification

factor, A was the area of the micrograph $\left(\right.$ in $\mathrm{cm}^{2}$ ), and $\Phi$ was the volume expansion ratio (VER) of the polymer foam [21]. 
The cell volume fraction distribution $V_{\mathrm{f}}$ was calculated using the following equation (6) [7]:

$$
V_{\mathrm{f}}=\left(\frac{\pi}{6}\right)\left[\frac{\sum_{i=1}^{n} d_{i}^{3}}{n}\right] N_{0}
$$

where $d_{\mathrm{i}}$ was the diameter of each counted cell.

\section{Results and discussion}

\subsection{Torque behavior of the samples}

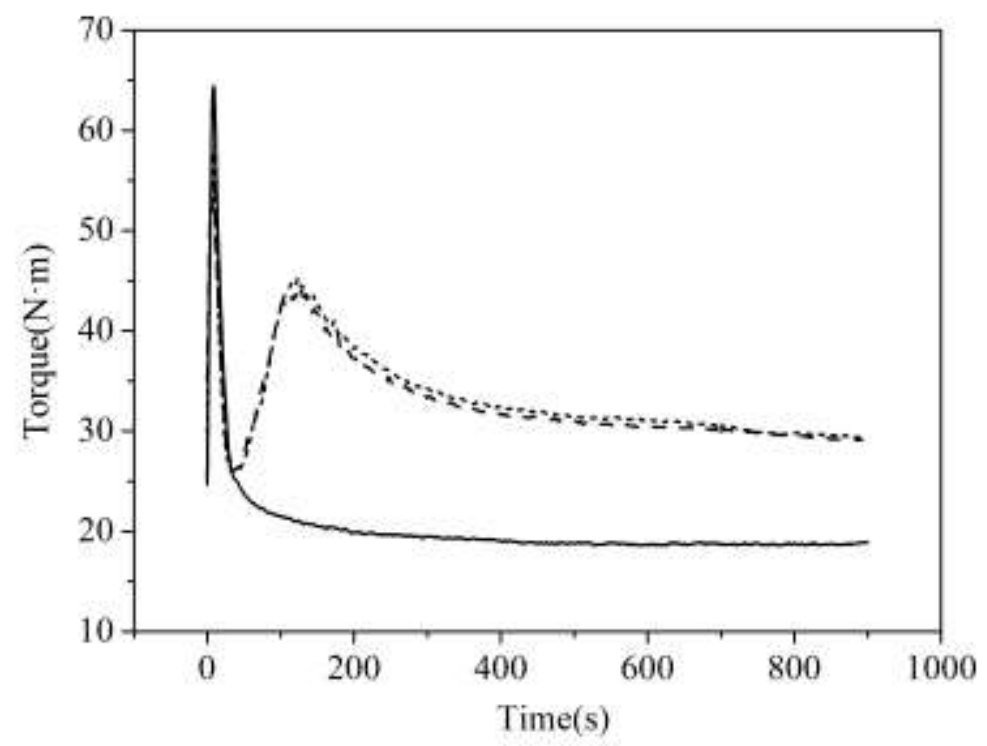

Fig. 2. Torque curves of various high-density polyethylene (HDPE) samples. The samples were prepared in a Haake internal mixer at $190{ }^{\circ} \mathrm{C}$, with a mixing time of 15 min and mixing speed of $60 \mathrm{rpm}$. (-) neat HDPE (1\#); (---) HDPE/dicumyl peroxide (DCP)-100/0.25 (2\#); (‥) HDPE/DCP/carbon nanotubes (CNTs)-100/0.25/0.10 (3\#).

The torque curves of the three HDPE samples were shown in Fig. 2. It could be found that the first peak of all the samples which was caused by the plasticizing of HDPE occurred at a same place. After the first peak, the torque value of neat HDPE sample (1\#) 
remained stable, while a second peak appeared in the torque curves of the HDPE samples (2\# and 3\#), which should be caused by the occurrence of cross-linking reaction. For the formation of cross-linking structure, the final torque values of the HDPE samples (2\# and 3\#) were significantly higher than that of neat HDPE sample (1\#) [22].

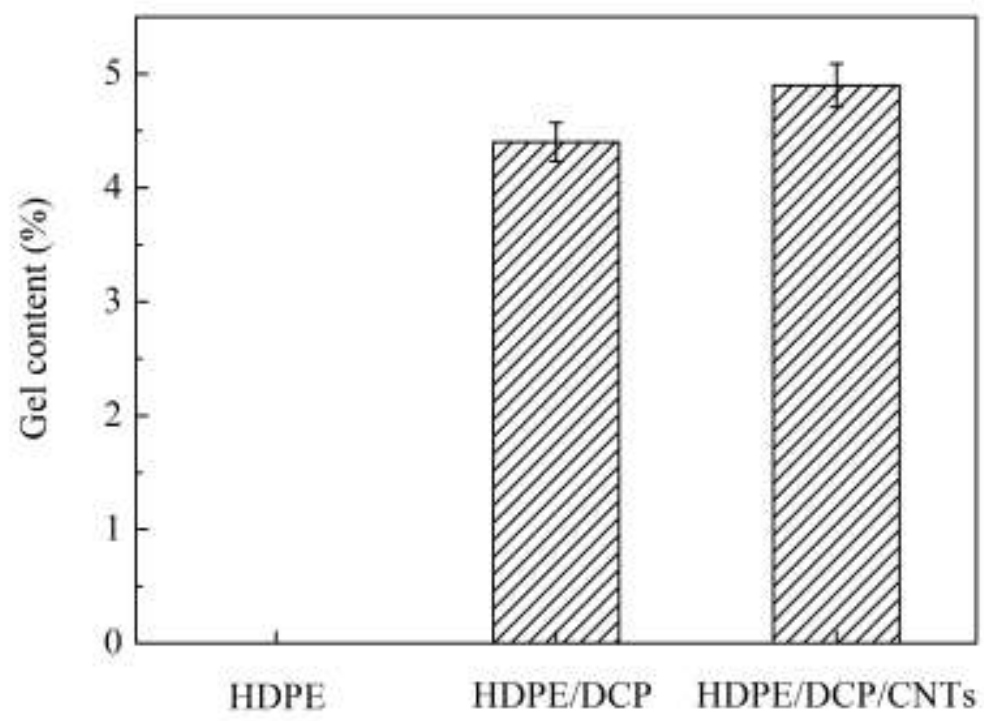

Fig. 3. Gel contents of various high-density polyethylene (HDPE) samples. neat HDPE (1\#); HDPE/dicumyl peroxide (DCP)-100/0.25 (2\#); HDPE/DCP/carbon nanotubes (CNTs)-100/0.25/0.10 (3\#).

Gel content could be employed to measure the cross-linking degree of the material. As shown in Fig. 3, the gel content of neat HDPE sample (1\#) was zero, while the gel content of the HDPE samples (2\# and 3\#) were 4.4 and 4.9\%, respectively. It confirmed that some network structures formed in the HDPE samples (2\# and 3\#) after adding DCP. The fact that the gel content of the HDPE sample (3\#) was higher than that of the HDPE sample (2\#) maybe due to the large specific surface area and pore structure of CNTs. DCP could be adsorbed on the surface of CNTs surface, avoiding the agglomeration of 
DCP, which was beneficial to the reaction between DCP and HDPE. It also confirmed the inference discussed about Fig.2.

\subsection{Crystallization and melting behavior}

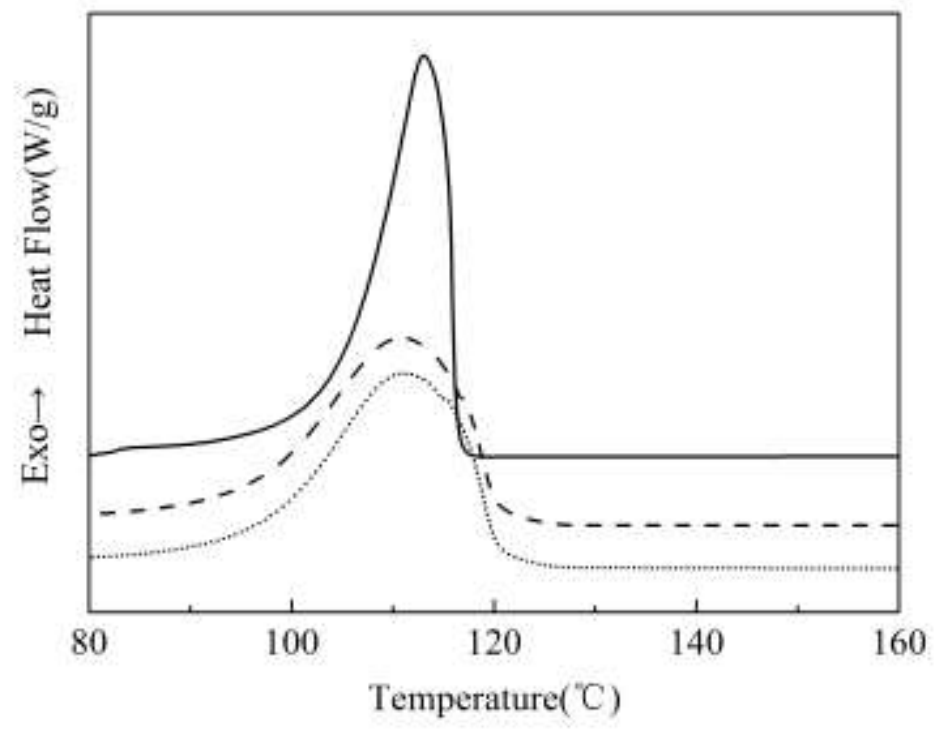

Fig. 4. DSC curves of various high-density polyethylene (HDPE) samples at cooling rate of $20{ }^{\circ} \mathrm{C} / \mathrm{min}$. (-) neat HDPE (1\#); (---) HDPE/dicumyl peroxide (DCP)-100/0.25 (2\#); (‥) HDPE/DCP/carbon nanotubes (CNTs)-100/0.25/0.10 (3\#). 


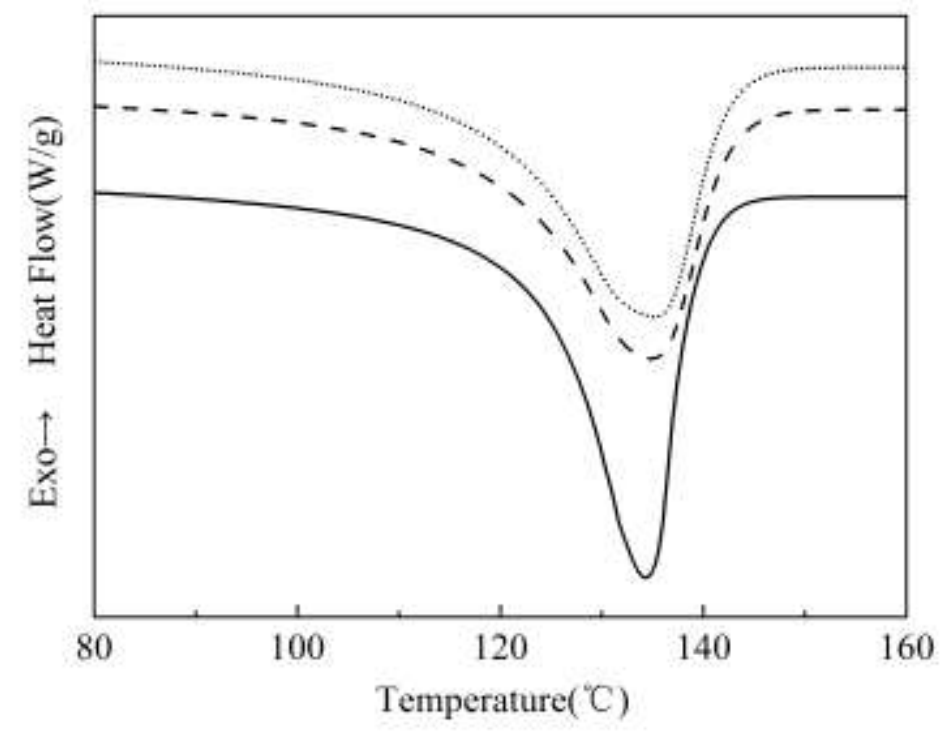

Fig. 5. DSC curves of various high-density polyethylene (HDPE) samples at heating rate of $20{ }^{\circ} \mathrm{C} / \mathrm{min}$. (-) neat HDPE (1\#); (---) HDPE/dicumyl peroxide (DCP)-100/0.25 (2\#); (‥) HDPE/DCP/carbon nanotubes (CNTs)-100/0.25/0.10 (3\#).

\section{Table 2}

Thermal properties $\left(T_{\mathfrak{c}}, \Delta H_{\mathfrak{c}}, T_{\mathrm{m}}, \chi_{\mathrm{c}}\right)$ of various high-density polyethylene (HDPE) samples at heating/cooling rate of $20^{\circ} \mathrm{C} / \mathrm{min}$.

\begin{tabular}{cccc}
\hline Samples & HDPE $(1 \#)$ & HDPE/DCP (2\#) & HDPE/DCP/CNTs (3\#) \\
\hline$T_{\mathrm{c}}\left({ }^{\circ} \mathrm{C}\right)$ & 113.2 & 110.8 & 111.0 \\
$\Delta H_{\mathrm{c}}(\mathrm{J} / \mathrm{g})$ & 198.3 & 177.3 & 182.0 \\
$T_{\mathrm{m}}\left({ }^{\circ} \mathrm{C}\right)$ & 134.2 & 134.7 & 135.4 \\
$\chi_{\mathrm{c}}(\%)$ & 68.4 & 61.1 & 62.8 \\
\hline
\end{tabular}

Dicumyl peroxide and carbon nanotubes are denoted as DCP and CNTs, respectively. 
Solubilizing and foaming temperatures of the foaming process should be determined in reference with the melting and crystallization temperatures of a particular crystalline polymer, respectively. The crystallization and melting behavior of the HDPE samples was detected using DSC, resulting in curves in Figs. 4 and 5, with corresponding data summarized in Table 2. It could be observed form Figs. 4 that there existed big crystallization peaks in the three curves of DSC. Compared with these of neat HDPE sample (1\#), the crystallization temperature of the HDPE sample (2\#) decreased slightly from 113.2 to $110.8{ }^{\circ} \mathrm{C}$, and the crystallinity decreased from $68.4 \%$ to $61.1 \%$, which obviously because the formation of the cross-linking structure hindered the crystallization of HDPE due to the introduction of DCP. Compared with these of the HDPE sample (2\#), the crystallization temperature and crystallinity of the HDPE sample (3\#) increased slightly, which should be attributed to two competing effects. One is that CNTs acting as heterogeneous nucleating sites promoted the crystallization of HDPE, and the other is that the higher degree of cross-linking confined the crystallization of HDPE.

As shown from in Table 2, the melting points of the HDPE samples (2\# and 3\#) were somewhat higher than that of neat HDPE sample (1\#), which may be because the cross-linking structure hindered the movement of the molecular chain.

\subsection{Rheological Property}

The melt strength of neat HDPE was too low to meet the requirement for foaming process. To solve this problem, DCP was introduced into HDPE to fabricate cross-linking structures to enhance the melt strength, which could be characterized indirectly by complex viscosity $\left(\eta^{*}\right)$, storage modulus $\left(G^{\prime}\right)$ and loss angle $(\tan \delta)$ at different shear rates. 


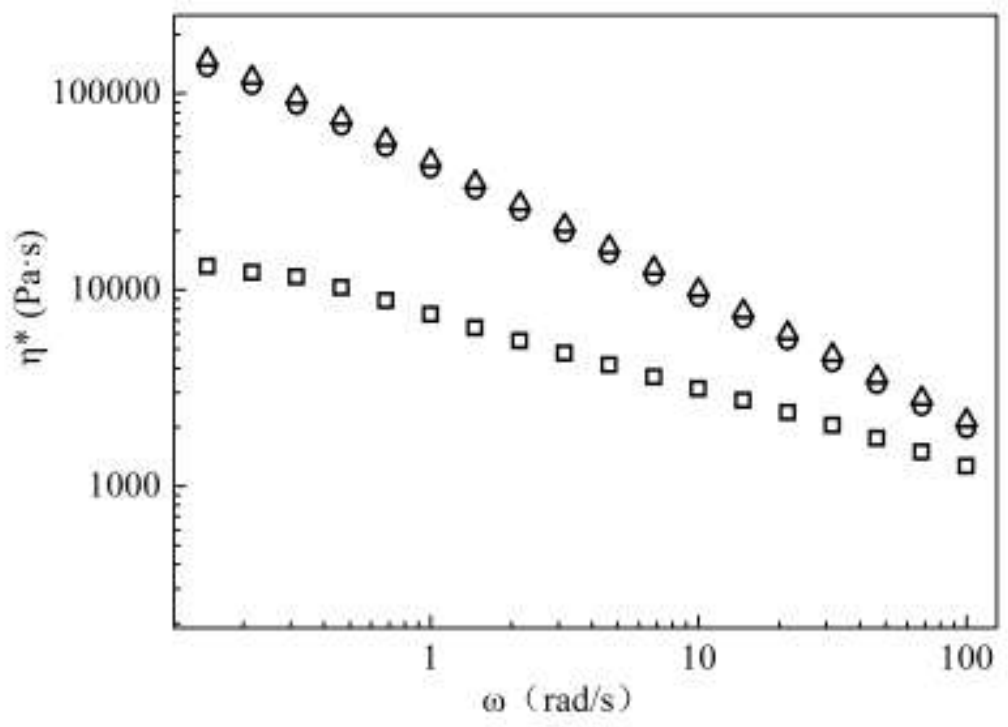

Fig. 6. Relationships between complex viscosity $\left(\eta^{*}\right)$ and shear rate for various high-density polyethylene (HDPE) samples. ( $\square$ ) neat HDPE (1\#); (०) HDPE/dicumyl peroxide (DCP)-100/0.25 (2\#); ( $\Delta$ ) HDPE/DCP/carbon nanotubes (CNTs)-100/0.25/0.10 (3\#).

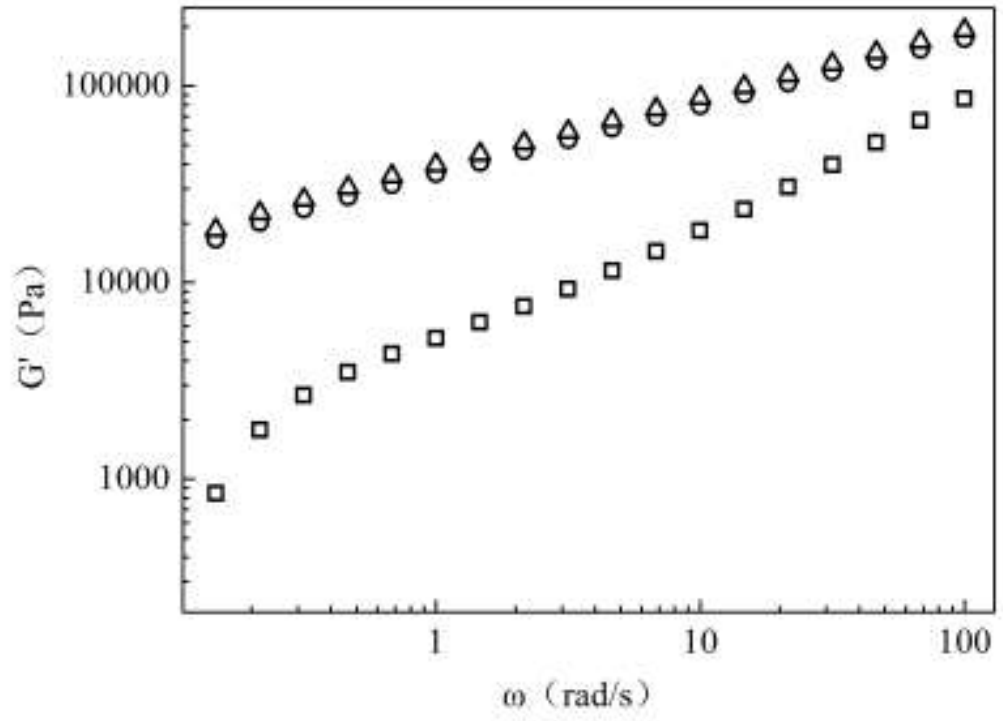


Fig. 7. Relationships between storage modulus (G') and shear rate for various high-density polyethylene (HDPE) samples. ( $\square$ ) neat HDPE (1\#); ( ०) HDPE/dicumyl peroxide (DCP)-100/0.25 (2\#); ( $\Delta$ ) HDPE/DCP/carbon nanotubes (CNTs)-100/0.25/0.10 (3\#).

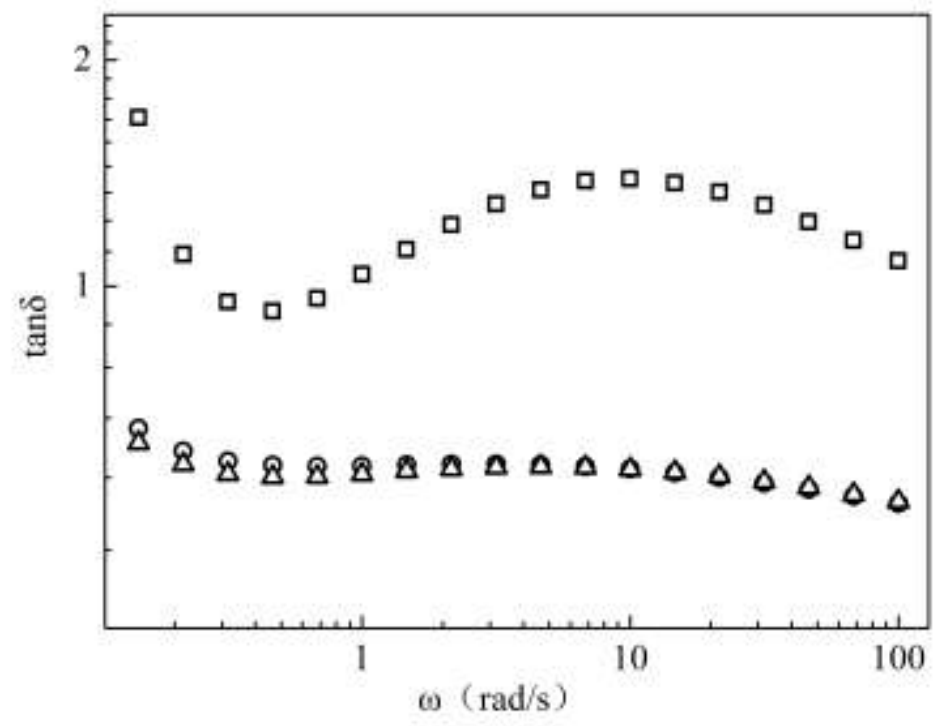

Fig. 8. Relationships between loss angle $(\tan \delta)$ and shear rate for various high-density polyethylene (HDPE) samples. ( $\square$ ) neat HDPE (1\#); (०) HDPE/dicumyl peroxide (DCP)-100/0.25 (2\#); (A) HDPE/DCP/carbon nanotubes (CNTs)-100/0.25/0.10 (3\#).

Fig. 6 showed the relationships of various HDPE samples between $\eta^{*}$ and shear rate. Comparing with neat HDPE sample (1\#), there was a steeper slope with no Newtonian plateau at low frequency in the curves of the HDPE samples (2\# and 3\#), which was typical for cross-linking systems. Besides that, the $\eta^{*}$ of the HDPE samples (2\# and 3\#) was higher than that of neat HDPE sample (1\#).

The melt elasticity could be characterized by the G' and $\tan \delta$. The G' increased and the $\tan \delta$ decreased, indicating that the melt elasticity enhanced [23]. Figs. 7 and 8 represented the storage modulus $\left(G^{\prime}\right)$ and loss angle $(\tan \delta)$ against shear rate for the three 
samples, respectively. It could be seen that the $G^{\prime}$ value of the HDPE samples (2\# and 3\#) was larger and their $\tan \delta$ value was smaller than the corresponding values of neat HDPE sample (1\#), which indicated that the melt elasticity of HDPE was enhanced by cross-linking [24].

3.4. Cellular Morphology 


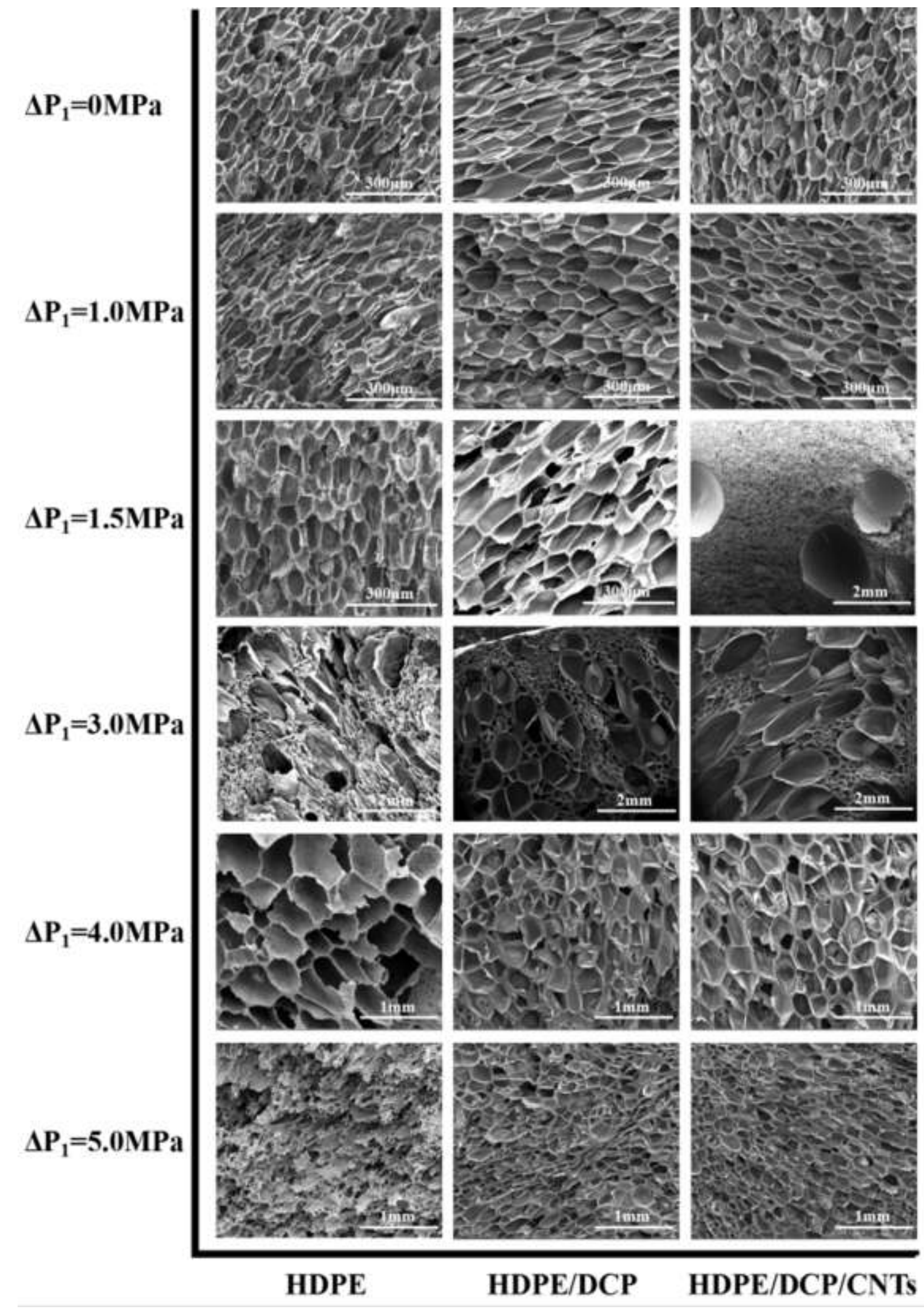


Fig. 9. SEM micrographs of different degree of the first depressurization $\left(\Delta \mathrm{P}_{1}\right)$ for various high-density polyethylene (HDPE) foaming samples. neat HDPE (1\#); HDPE/dicumyl peroxide (DCP)-100/0.25 (2\#); HDPE/DCP/carbon nanotubes (CNTs)-100/0.25/0.10 (3\#).

Fig. 9 showed the SEM micrographs of various HDPE foaming samples for different $\Delta \mathrm{P}_{1}$. It could be observed that when $\Delta \mathrm{P}_{1}$ was 0 and $1.0 \mathrm{MPa}$, all the HDPE foaming samples (1-3\#) were MCS. This suggested that there was no cell nucleation in the cooling stage and the first depressurization stage, the cell nucleation and growth only occurred in the second depressurization stage. The reason may be that there was a depressurization in the cooling stage, but the cooling time was too long, which led the depressurization rate was too slow to release enough energy to overcome Gibbs free energy for cell nucleating, and $\Delta \mathrm{P}_{1}$ was also not high enough to overcome Gibbs free energy for cell nucleating.

When $\triangle \mathrm{P}_{1}$ was increased to $1.5 \mathrm{MPa}$, CCS formed in the HDPE foaming sample (3\#), while the HDPE foaming samples (1\# and 2\#) were still MCS. This was because the pressure drop of 1.5 MPa in the first depressurization stage was still not high enough for cell nucleation in the HDPE foaming samples (1\# and 2\#).

The Gibbs free energy of homogeneous nucleation for the HDPE foaming samples (1\# and 2\#) could be calculated by equation (7), while the Gibbs free energy of heterogeneous nucleation for the HDPE foaming sample (3\#) was calculated by equations (8) and (9) [25].

$$
\begin{aligned}
& \Delta G_{\mathrm{hom}}^{*}=\frac{16 \pi}{3 \Delta P^{2}} \gamma_{b p}^{3} \\
& \Delta G_{\text {het }}^{*}=\frac{16 \pi}{3 \Delta P^{2}} \gamma_{b p}^{3} S(\theta)=\Delta G_{\mathrm{hom}}^{*} S(\theta) \\
& S(\theta)=\frac{1}{4}(2+\cos \theta)(1-\cos \theta)^{2}
\end{aligned}
$$


Where $\Delta G$ was the Gibbs free energy for cell nucleation, $\Delta \mathrm{P}=\mathrm{P}_{\text {sat }}-\mathrm{P}_{\mathrm{s}}$ was the supersaturated pressure. For a microcellular process system, $\mathrm{P}_{\text {sat }}$ was the gas saturation pressure and $\mathrm{P}_{\mathrm{s}}$ was the surrounding pressure at which nucleation was to occur. Usually, $\mathrm{P}_{\mathrm{s}}$ was supposed to equal to atmospheric pressure. $\gamma_{\mathrm{bp}}$ was the surface tension of the polymer. $\theta$ was the wetting angle of the interface between polymer and CNTs.

For the HDPE foaming sample (3\#), the $\theta$ was between 0 and $\pi$, and $S(\theta)$ was less than 1, so the Gibbs free energy of heterogeneous nucleation for the HDPE foaming sample (3\#) was lower than these of homogeneous nucleation for the HDPE foaming samples (1\# and 2\#). That was why the CCS appeared in the HDPE foaming sample (3\#) at lower $\Delta \mathrm{P}_{1}$.

When $\triangle \mathrm{P}_{1}$ was $3.0 \mathrm{MPa}$, all the HDPE foaming samples (1-3\#) possessed CCS. When $\Delta \mathrm{P}_{1}$ increased to $4.0 \mathrm{MPa}$, the $\mathrm{CCS}$ in all the HDPE foaming samples (1-3\#) disappeared. The reason for this phenomenon was that the pressure drop of 4.0 $\mathrm{MPa}$ in the first depressurization stage was high enough for too many cells nucleating and growing in the holding time, which would lead to no space for small cells nucleating and growing in the second depressurization stage. When $\Delta \mathrm{P}_{1}$ reached $5.0 \mathrm{MPa}$, the cells of neat HDPE foaming samples (1\#) were ruptured. This maybe because $\Delta \mathrm{P}_{1}$ of $5.0 \mathrm{MPa}$ was so high that resulted in more cells with thinner cell wall at the first depressurization stage, compared with the other lower $\Delta \mathrm{P}_{1}$. The resultant cell would undergo further growth with a long time at the holding time and further intense growth at the second depressurization stage. The lower melt strength of neat HDPE could not support the further growth at the holding time and the second depressurization stage; as a result, the thin cell wall was ruptured. Whereas the cellular structure of the HDPE foaming samples (2\# and 3\#) was unbroken, which should be attributed to the improved melt strength of HDPE by cross-linking.

\section{Table 3}


Cell size and cell density of the different degree of the first depressurization for various high-density polyethylene (HDPE) foaming samples.

\begin{tabular}{|c|c|c|c|c|c|c|c|}
\hline $\begin{array}{l}\text { Th } \\
\text { dep }\end{array}$ & $\begin{array}{l}\text { legree of the first } \\
\text { ssurization (MPa) }\end{array}$ & 0 & 1.0 & 1.5 & 3.0 & 4.0 & 5.0 \\
\hline \multirow{5}{*}{$\begin{array}{l}\text { HDPE } \\
(1 \#)\end{array}$} & Large cell size $(\mu \mathrm{m})$ & - & - & - & 973 & 623 & - \\
\hline & Large cell density & & & & & & \\
\hline & $\left(\right.$ cells $\left./ \mathrm{cm}^{3}\right)$ & - & - & - & $5.1 \times 10^{6}$ & $3.3 \times 10^{7}$ & - \\
\hline & Small cell size $(\mu \mathrm{m})$ & 88 & 87 & 98 & 160 & - & - \\
\hline & $\begin{array}{l}\text { Small cell density } \\
\left(\text { cells } / \mathrm{cm}^{3}\right)\end{array}$ & $3.0 \times 10^{9}$ & $3.3 \times 10^{9}$ & $1.9 \times 10^{9}$ & $4.2 \times 10^{8}$ & - & - \\
\hline \multirow{4}{*}{$\begin{array}{c}\text { HDPE/ } \\
\text { DCP } \\
(2 \#)\end{array}$} & Large cell size $(\mu \mathrm{m})$ & - & - & - & 964 & 323 & 180 \\
\hline & $\begin{array}{l}\text { Large cell density } \\
\qquad\left(\text { cells } / \mathrm{cm}^{3}\right)\end{array}$ & - & - & - & $1.1 \times 10^{7}$ & $2.1 \times 10^{8}$ & $4.3 \times 10^{8}$ \\
\hline & Small cell size $(\mu \mathrm{m})$ & 112 & 116 & 117 & 183 & - & - \\
\hline & $\begin{array}{l}\text { Small cell density } \\
\left(\text { cells } / \mathrm{cm}^{3}\right)\end{array}$ & $2.4 \times 10^{9}$ & $2.0 \times 10^{9}$ & $1.2 \times 10^{9}$ & $1.1 \times 10^{8}$ & - & - \\
\hline & Large cell size $(\mu \mathrm{m})$ & - & - & 1736 & 1207 & 393 & 192 \\
\hline $\begin{array}{l}\mathrm{HDPE} / \\
\mathrm{DCP} / \mathrm{C}\end{array}$ & $\begin{array}{l}\text { Large cell density } \\
\qquad\left(\text { cells } / \mathrm{cm}^{3}\right)\end{array}$ & - & - & $1.4 \times 10^{5}$ & $1.3 \times 10^{7}$ & $1.3 \times 10^{8}$ & $4.7 \times 10^{8}$ \\
\hline NTs & Small cell size $(\mu \mathrm{m})$ & 77 & 92 & 124 & 220 & - & - \\
\hline$(3 \#)$ & $\begin{array}{l}\text { Small cell density } \\
\left(\text { cells } / \mathrm{cm}^{3}\right)\end{array}$ & $4.5 \times 10^{9}$ & $3.8 \times 10^{9}$ & $1.0 \times 10^{9}$ & $6.4 \times 10^{7}$ & - & - \\
\hline
\end{tabular}

Dicumyl peroxide and carbon nanotubes are denoted as DCP and CNTs, respectively. 

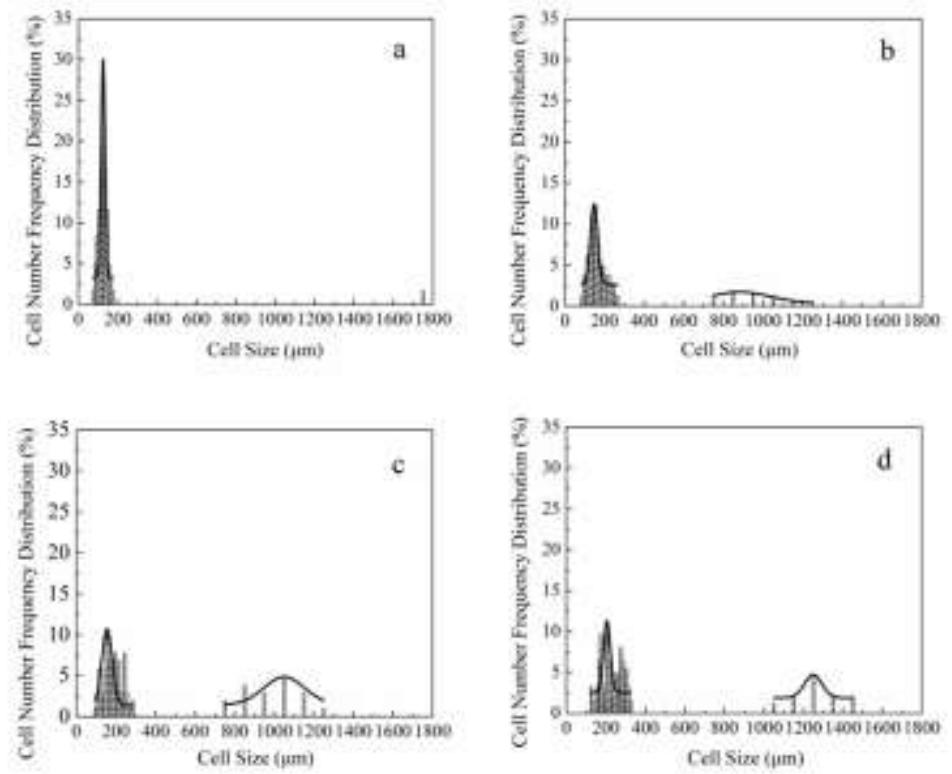

Fig. 10. Cell number frequency distribution of various high-density polyethylene (HDPE) foaming samples with complex cellular structure. a: HDPE/dicumyl peroxide (DCP)/carbon nanotubes (CNTs)-100/0.25/0.10 (3\#), $\Delta \mathrm{P}_{1}=1.5 \mathrm{MPa}$; b: neat HDPE (1\#), $\Delta \mathrm{P}_{1}=3.0 \quad \mathrm{MPa} ; \quad \mathrm{c}: \quad$ HDPE/DCP-100/0.25 $\quad$ (2\#), $\Delta \mathrm{P}_{1}=3.0 \quad \mathrm{MPa} ; \mathrm{d}$ : HDPE/DCP/CNTs-100/0.25/0.10 (3\#), $\Delta \mathrm{P}_{1}=3.0 \mathrm{MPa} . \Delta \mathrm{P}_{1}$ represented the degree of the first depressurization. 

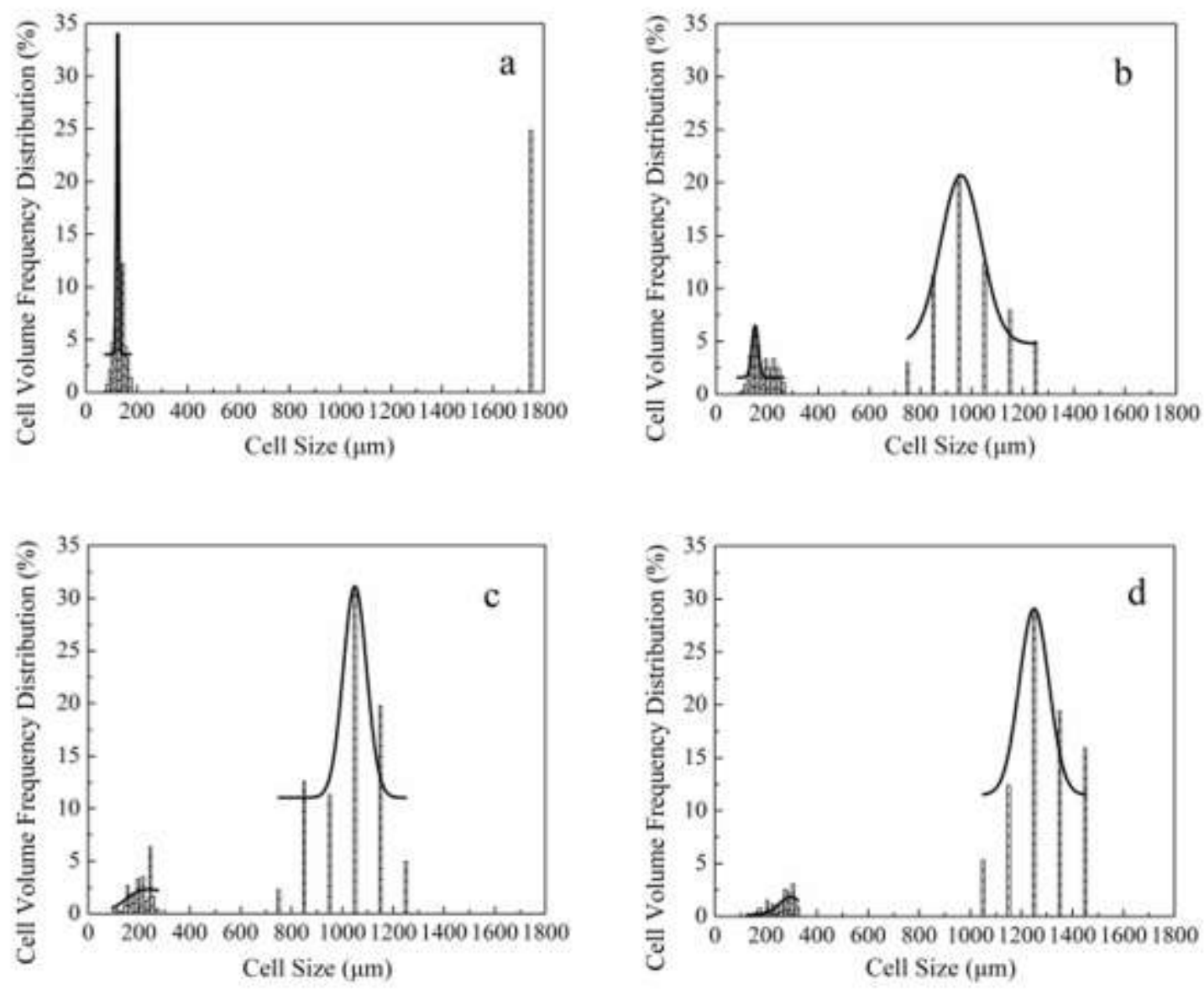

Fig. 11. Cell volume frequency distribution of various high-density polyethylene (HDPE) foaming samples with complex cellular structure. a: HDPE/dicumyl peroxide (DCP)/carbon nanotubes (CNTs)-100/0.25/0.10 (3\#), $\Delta \mathrm{P}_{1}=1.5 \mathrm{MPa}$; b: neat HDPE (1\#), $\Delta \mathrm{P}_{1}=3.0 \quad \mathrm{MPa} ; \quad \mathrm{c}: \quad \mathrm{HDPE} / \mathrm{DCP}-100 / 0.25 \quad(2 \#), \quad \Delta \mathrm{P}_{1}=3.0 \quad \mathrm{MPa} ; \mathrm{d}:$ HDPE/DCP/CNTs-100/0.25/0.10 (3\#), $\Delta \mathrm{P}_{1}=3.0 \mathrm{MPa} . \Delta \mathrm{P}_{1}$ represented the degree of the first depressurization.

Cell size and cell density for various $\Delta \mathrm{P}_{1}$ of the samples were listed in Table 3 . The cell size distributions of the four samples with CCS based on the area occupied and cell number frequency distribution by the cells of different size were shown in Figs. 10 and 11. When $\triangle \mathrm{P}_{1}$ was $1.0 \mathrm{MPa}$, all the HDPE foaming samples (1-3\#) possessed a MCS with average cell size of about $100 \mu \mathrm{m}$ and cell density of about $3 \times 10^{9}$ cells $/ \mathrm{cm}^{3}$. Comparing 
the foaming samples with $\Delta \mathrm{P}_{1}$ of 1.0 and $0 \mathrm{MPa}$ (one-step depressurization method), one may find their cell size and density were similar, this meant that a minor first depressurization had no effect on these values, because it was too low to induce cell nucleation.

When $\triangle \mathrm{P}_{1}$ was $1.5 \mathrm{MPa}$, the HDPE foaming samples (1\# and 2\#) still had MCS, and their cell size and density were like those prepared with $\Delta \mathrm{P}_{1}$ of 0 and $1.0 \mathrm{MPa}$. However, CCS appeared in the HDPE foaming sample (3\#) with large cell size of $1736 \mu \mathrm{m}$ and density of $1.4 \times 10^{5}$ cells $/ \mathrm{cm}^{3}$, small cell size of $124 \mu \mathrm{m}$ and density of $1.0 \times 10^{9}$ cells $/ \mathrm{cm}^{3}$. This should be attributed to the introduction of CNTs which induced the decrease of the barrier of cell nucleation. As shown in Figs 10 and 11, the cell number frequency distribution of large cell size was less than $5 \%$ and the cell volume frequency distribution of large cell size was nearly $25 \%$.

When $\triangle \mathrm{P}_{1}$ increased to 3.0 MPa, CCS was formed in all the HDPE foaming samples. The large cell and small cell in the HDPE foaming samples (1\# and 2\#) were similar in size and the cell density, respectively. But the behavior in the HDPE foaming sample (3\#) was different. When $\Delta \mathrm{P}_{1}$ increased from 1.5 to $3.0 \mathrm{MPa}$, its large cell size decreased from 1736 to $1207 \mu \mathrm{m}$ and its large cell density increased from $1.4 \times 10^{5}$ to $1.3 \times 10^{7}$ cells $/ \mathrm{cm}^{3}$ due to the increment of the first depressurization rate. By contrast, its small cell size increased from 124 to $220 \mu \mathrm{m}$ and its small cell density decreased from $1.0 \times 10^{9}$ to $6.4 \times 10^{7}$ cells $/ \mathrm{cm}^{3}$ due to the decrement of the second depressurization rate. In Figs. 10 and 11, it could be found that the ratio of cell number frequency distribution and cell volume frequency distribution of large cell and small cell of the HDPE foaming samples (2\# and 3\#) were both higher than those of the neat HDPE foaming samples (1\#), indicating that cross-linking was beneficial to increase the cell number frequency distribution and cell volume frequency distribution of large cell. However, the ratio of cell number frequency distribution and cell volume frequency distribution of large cell and small cell of the HDPE foaming samples (2\#) were like that of the HDPE foaming 
sample (3\#), implying that the introduction of CNTs had little effect on the ratio of cell number frequency distribution and cell volume frequency distribution of large cell and small cell.

Interestingly, when $\Delta \mathrm{P}_{1}$ reached 4.0 $\mathrm{MPa}, \mathrm{CCS}$ disappeared in all the HDPE foaming samples (1-3\#) and MCS occurred again. This should be due to that more cells nucleated at the first depressurization stage and no place remained for the second cell nucleation at the second depressurization stage. Compared with the MCS samples formed at lower $\Delta \mathrm{P}_{1}$, all the samples with $\Delta \mathrm{P}_{1}$ of $4.0 \mathrm{MPa}$ took on larger cell size and smaller cell density. This was because that the depressurization rate at the first depressurization stage was lower than that at the second depressurization stage.

With $\Delta \mathrm{P}_{1}$ increased to 5.0 $\mathrm{MPa}$, the cell size of the HDPE foaming samples (2\# and 3\#) decreased and their density increased, due to the increment of the first depressurization rate. Since the cells of neat HDPE foaming sample (1\#) was ruptured, their cell size and cell density could not be calculated.

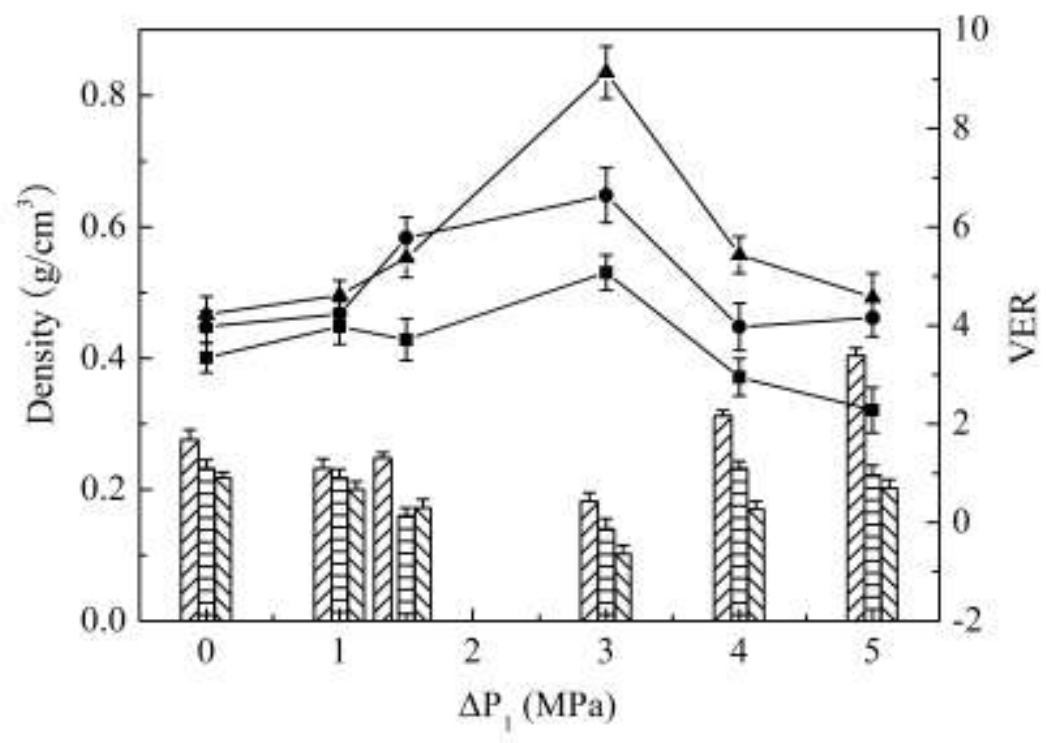

Fig. 12. Densities and volume expansion ratio (VER) of various high-density polyethylene (HDPE) foaming samples with different degree of the first depressurization 
$\left(\triangle \mathrm{P}_{1}\right)$. (ZU/) density of neat HDPE (1\#); ( $($ ) density of HDPE/dicumyl peroxide (DCP)-100/0.25 (2\#); ( $\mathbb{M}$ ) density of HDPE/DCP/carbon nanotubes (CNTs)-100/0.25/0.10 (3\#); (- —) VER of neat HDPE (1\#); (- - VER of HDPE/dicumyl peroxide (DCP)-100/0.25 (2\#); (一 -) VER of HDPE/DCP/carbon nanotubes (CNTs)-100/0.25/0.10 (3\#).

Fig. 12 summarized the density and VER of the HDPE foaming samples (1-3\#) with different $\Delta \mathrm{P}_{1}$. It could be observed that under the same $\Delta \mathrm{P}_{1}$, the VER of most foam increased with increasing gel content. This may be because the cross-linked structure improved the melt strength of HDPE and thus the foaming behavior. With $\Delta \mathrm{P}_{1}$ increasing, the VER of the HDPE foaming samples (1-3\#) rose first and then declined. When $\Delta \mathrm{P}_{1}$ was 3.0 MPa, the VER of the HDPE foaming samples (1-3\#) gave rise to the maximum value, which may be resulted from the existence of the large cells. When $\Delta \mathrm{P}_{1}$ was below 3.0 $\mathrm{MPa}$, the number of large cells increased with increasing degree of first depressurization, which was beneficial to decrease the density of the foam. When $\Delta \mathrm{P}_{1}$ was over 3.0 MPa, the large cells disappeared and the density of all the HDPE foaming samples (1-3\#) increased.

\section{Mechanism for the formation of CCS}

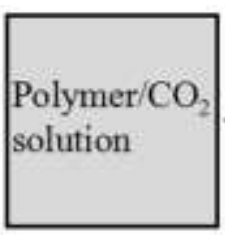

(a)

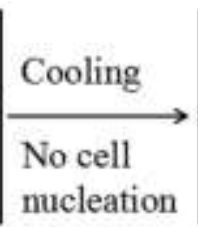

nucleation

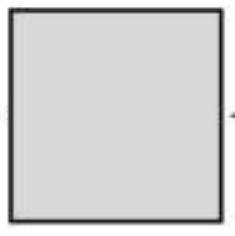

(b)

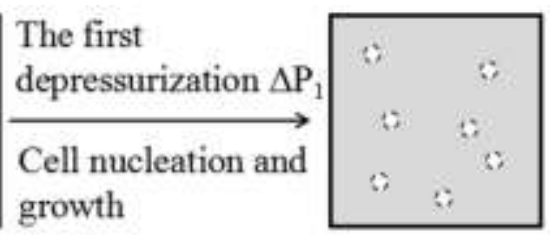

(c)

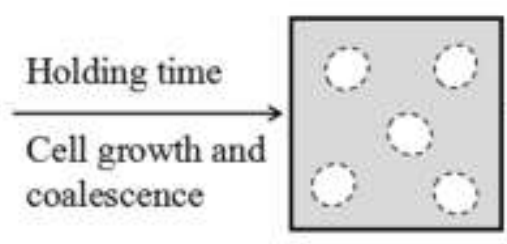

(d)

The second depressurization $\Delta \mathrm{P}_{2}$ The large cell growth and coalescence. The small cell nucleation and growth

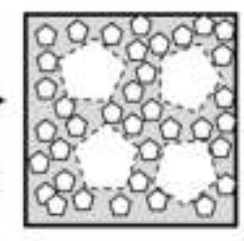

(e) 
Fig. 13. Schematic diagram for the formation of CCS

The schematic diagram for the formation of CCS in HDPE was shown in Fig. 13, which included five stages during the foaming processing: immersing stage, cooling stage, first depressurization, holding stage, and second depressurization. For comparison, in this study, each sample was treated in the same condition.

(1) Immersing Stage: Various HDPE samples were immersed in an autoclave with a pressure of $\mathrm{CO}_{2}$ at $20 \mathrm{MPa}$ for $2 \mathrm{~h}$ (Fig. 13a), and then $\mathrm{HDPE} / \mathrm{CO}_{2}$ homogenous solution was formed. Owing to the higher diffusion coefficient of $\mathrm{CO}_{2}$ in the polymer melt at higher temperature, $\mathrm{HDPE}$ melt and $\mathrm{CO}_{2}$ reached an equilibrium in a short time [26, 27].

(2) Cooling Stage: The temperature was cooled from 200 to $135{ }^{\circ} \mathrm{C}$ (Fig. 13b) to increase the melt strength of HDPE. Although a big degree of depressurization occurred during the cooling stage, there was no cell nucleation since the cooling time was very long and the depressurization rate was very low. Similar phenomena were observed in our previous researches [28, 29].

(3) The first Depressurization: Some cells would nucleate, shown in Fig. 13c. Importantly, $\Delta \mathrm{P}_{1}$ should be at a proper degree, neither too low nor too high. If $\Delta \mathrm{P}_{1}$ was too low, it would not overcome nucleation energy barrier and induce the first nucleation. On the other hand, if $\Delta \mathrm{P}_{1}$ was too high, numerous cells would form resulting in no unfoamed region for the second nucleation to occur [7]. Similar phenomenon was also observed in our previous research [30].

(4) Holding Time: After the first depressurization, the state of foaming system would be maintained for a desired time, in which the bubbles would grow and coalesce. During this stage (Fig. 13d), the main driving force for bubbles growth is derived from the supersaturated gas from the unfoamed regions, which would diffuse into the existing cells [31]. Meanwhile, with the growth of the bubbles, the cell walls would become thin resulting from the difference between the pressure in the cell and the pressure in the cell 
wall, which would break when it reached critical thickness [32]. During this stage, the size of existed bubbles became more and more large, and it would become the large cells in the final foam, which would be helpful to the decrease of the cell density.

(5) The Second Depressurization: The residual pressure would be released completely to ambient pressure in the second depressurization. During this stage (Fig. 13e), the bubbles, which created in the first depressurization step, would continue growing and coalescing, resulting in the final large cells. The small cells would create in unfoamed region. If there were not enough space available for the nucleation and growth of the small cell in this stage, only one cell size (i.e. MCS) would be obtained.

\section{Conclusion}

HDPE foams with CCS were prepared using a cooling and two-step depressurization method. DCP was added into HDPE as a cross-linking agent, which improved the viscoelasticity and foaming property. CNTs were introduced into HDPE as a nucleating agent, which decreased the nucleated energy barrier and increased the cell density. The cellular structure evolution in HDPE foam could be adjusted by the degree of depressurization in the first step, which was a key factor for the formation of CCS. When the degree of depressurization in the first step was 3.0 MPa, all the HDPE samples could be foamed with CCS, and the volume expansion ratio of the HDPE sample could reach 9.

\section{Acknowledgement}

This work was supported by the National Key Research and Development Program of China (2016YFB0302203 and 2016YFB0302205), the Natural Science Foundation of Beijing (2164058 and 2162012), and the National Science Foundation of China (51673004). 


\section{References}

[1] C. Zhang, B. Zhu, D. Li, L.J. Lee, Extruded polystyrene foams with bimodal cell morphology, Polymer 53 (2012) 2435-2442.

[2] K. Lee, E.K. Lee, S.G. Kim, C.B. Park, H.E. Naguib, Bi-cellular foam structure of polystyrene from Extrusion Foaming Process, J. Cell. Plast. 45 (2009) 539-553.

[3] C. Zhang, B. Zhu, L.J. Lee, Extrusion foaming of polystyrene/carbon particles using carbon dioxide and water as co-blowing agents, Polymer 52 (2011) 1847-1855.

[4] Z. Ma, G. Zhang, Q. Yang, X. Shi, A. Shi, Fabrication of microcellular polycarbonate foams with unimodal or bimodal cell-size distributions using supercritical carbon dioxide as a blowing agent, J. Cell. Plast. 50 (2014) 55-79.

[5] Z. Ma, G. Zhang, Q. Yang, X. Shi, Y. Liu, Mechanical and dielectric properties of microcellular polycarbonate foams with unimodal or bimodal cell-size distributions, J. Cell. Plast. 51 (2015) 307-327.

[6] J. Bao, G. Weng, L. Zhao, Z. Liu, Z. Chen, Tensile and impact behavior of polystyrene microcellular foams with bi-modal cell morphology, J. Cell. Plast. 50 (2014) 381-393.

[7] J. Bao, T. Liu, L. Zhao, G. Hu, A two-step depressurization batch process for the formation of bi-modal cell structure polystyrene foams using $\mathrm{scCO}_{2}$, J. Supercrit. Fluids 55 (2011) 1104-1114.

[8] A. Salerno, S. Zeppetelli, E.D. Maio, S. Iannace, P.A. Netti, Design of bimodal PCL and PCL-HA nanocomposite scaffolds by two step depressurization during solid-state supercritical $\mathrm{CO}_{2}$ foaming, Macromol. Rapid Comm. 32 (2011) 1150-1156.

[9] X. Jiang, T. Liu, L. Zhao, Z. Xu, W. Yuan, Effects of blend morphology on the foaming of polypropylene/low-density polyethylene blends during a batch foaming process, J. Cell. Plast. 45 (2009) 225- 241.

[10] K. Wang, Y. Pang, F. Wu, W. Zhai, W. Zheng, Cell nucleation in dominating formation of bimodal cell structure in polypropylene/polystyrene blend foams prepared via continuous extrusion with supercritical $\mathrm{CO}_{2}$, J. Supercrit. Fluids 110 (2016) 65-74. 
[11] Z. Duan, J. Ma, C. Xue, F. Deng, Effect of stearic acid/organic montmorillonite on EVA/SA/OMMT nanocomposite foams by melting blending, J. Cell. Plast. 50 (2014) 263-277.

[12] L. Tang, W. Zhai, W. Zheng, Autoclave preparation of expanded polypropylene/poly(lactic acid) blend bead foams with a batch foaming process, J. Cell. Plast. 47 (2011) 429-446.

[13] D. Kohlhoff, A. Nabil, M. Ohshima, In situ preparation of cross-linked polystyrene/ poly (methyl methacrylate) blend foams with a bimodal cellular structure, Polym. Advan. Technol. 23 (2012) 1350-1356.

[14] D. Li, T. Liu, L. Zhao, W. Yuan, Foaming of linear isotactic polypropylene based on its non-isothermal crystallization behaviors under compressed $\mathrm{CO}_{2}$, J. Supercrit. Fluids 60 (2011) 89-97.

[15] Z. Xing, G. Wu, S. Huang, S. Chen, H. Zeng, Preparation of microcellular cross-linked polyethylene foams by a radiation and supercritical carbon dioxide approach, J. Supercrit. Fluids 47 (2008) 281-289.

[16] B. Wang, M. Wang, Z. Xing, H. Zeng, G. Wu, Preparation of radiation crosslinked foams from low-density polyethylene/ethylene-vinyl acetate (LDPE/EVA) copolymer blend with a supercritical carbon dioxide approach, J. Appl Polym. Sci. 127 (2013) 912-918.

[17] M.M. Khorasani, S.R. Ghaffarian, A. Babaie, N. Mohammadi, Foaming behavior and cellular structure of microcellular HDPE nanocomposites prepared by a high temperature process, J. Cell. Plast. 46 (2010) 173-190.

[18] H. Zhang, G.M. Rizvi, C.B. Park, Development of an extrusion system for producing fine-celled HDPE/wood-fiber composite foams using $\mathrm{CO}_{2}$ as a blowing agent, Adv. Polym. Tech. 23 (2004) 263-276.

[19] R. Spina, Technological characterization of PE/EVA blends for foam injection molding, Mater. Design 84 (2015) 64-71. 
[20] A. Choudhury, Isothermal crystallization and mechanical behavior of ionomer treated sisal/HDPE composites, Mat. Sci. Eng. A-Struct. 491 (2008) 492-500.

[21] X. Xu, C.B. Park, D. Xu, R. Pop-iliev, Effects of die geometry on cell nucleation of PS foams blown with $\mathrm{CO}_{2}$, Polym. Eng. Sci. 43 (2003) 1378-1390.

[22] H. Azizi, J. Morshedian, M. Barikani, M.H. Wagner, Correlation between molecular structure parameters and network properties of silane-grafted and moisture cross-linked polyethylenes, Adv. Polym. Tech. 30 (2011) 286-300.

[23] H. Liu, X. Wang, W. Liu, B. Liu, H. Zhou, W. Wang, Reactive modification of poly (ethylene terephthalate) and its foaming behavior, Cell. Polym. 33 (2014) 189-212.

[24] H. Liu, X. Wang, H. Zhou, W. Liu, B. Liu, The preparation and characterization of branching poly(ethylene terephthalate) and its foaming behavior, Cell. Polym. 34 (2015) 63-94.

[25] J.S. Colton, N.P. Suh, The nucleation of microcellular thermoplastic foam with additives: Part I: theoretical considerations, Polym. Eng. Sci. 27 (1987) 485-492.

[26] B. Thitakamol, A. Veawab, Foaming model for $\mathrm{CO}_{2}$ absorption process using aqueous monoethanolamine solutions, Colloid. Surface. A 349 (2009) 125-136.

[27] N.S. Ramesh, D.H. Rasmussen, G.A. Campbell, Numerical and experimental studies of bubble growth during the microcellular foaming process, Polym. Eng. Sci. 31 (1991) $1657-1664$.

[28] X. Wang, W. Liu, H. Zhou, B. Liu, H. Li, Z. Du, C. Zhang, Study on the effect of dispersion phase morphology on porous structure of poly (lactic acid)/poly (ethylene terephthalate glycol-modified) blending foams, Polymer 54 (2013) 5839-5851.

[29] H. Zhou, X. Wang, Z. Du, H. Li, K. Yu, Preparation and characterization of chain extended poly(butylene succinate) foams, Polym. Eng. Sci. 55 (2015) 988-994.

[30] X. Wang, W. Wang, B. Liu, Z. Du, X. Peng, Complex cellular structure evolution of polystyrene/poly(ethylene terephthalate glycol-modified) foam using a two-step depressurization batch foaming process, J. Cell. Plast. 52 (2016) 595-618. 
[31] K.A. Arora, A.J. Lesser, T.J. McCarthy, Preparation and characterization of microcellular polystyrene foams processed in supercritical carbon dioxide, Macromolecules 31 (1998) 4614-4620.

[32] S.T. Lee, C.B. Park, N.S. Ramesh, Polymeric foams, Boca Raton: CRC Press, 2006. 


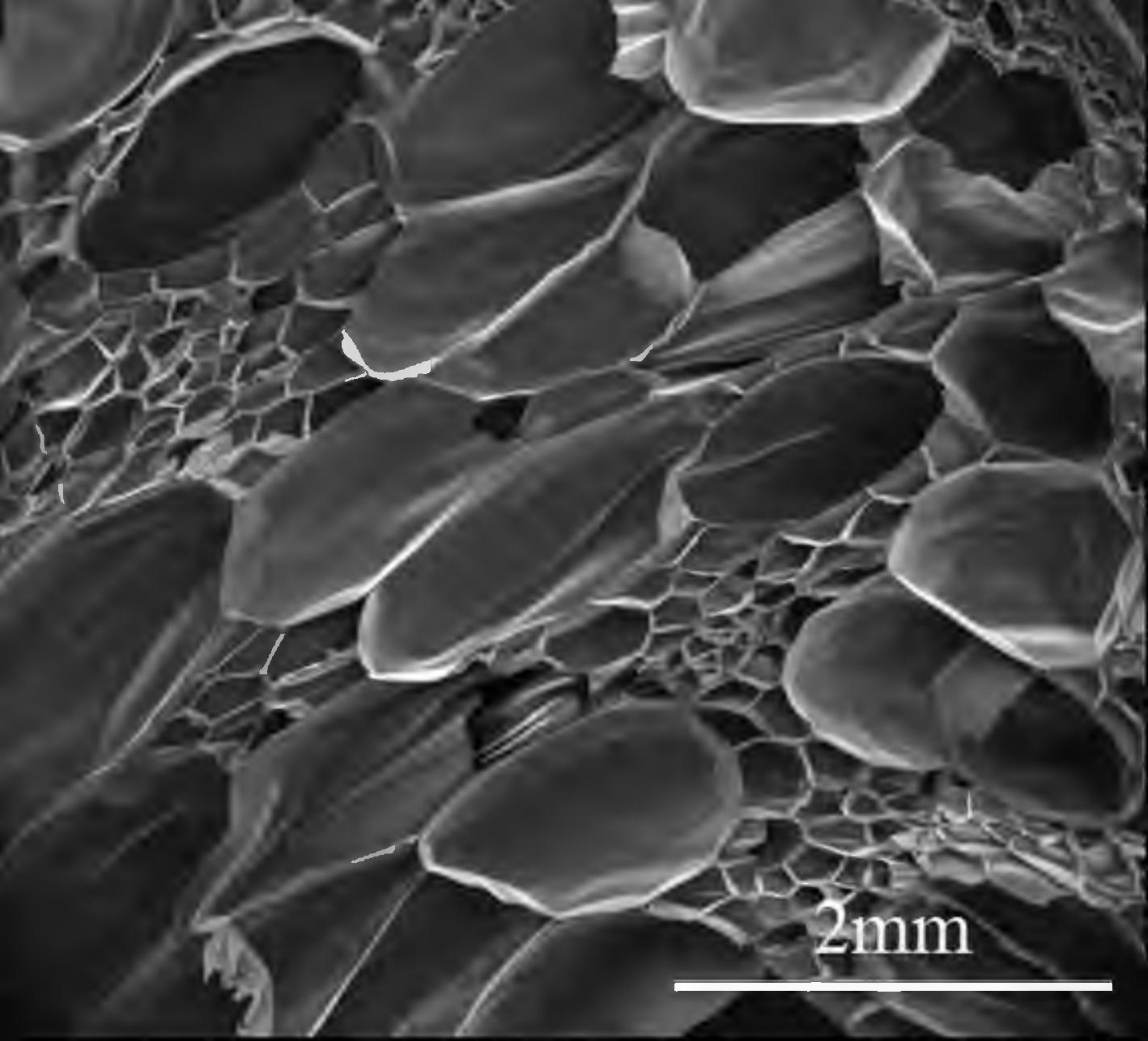

